\title{
Energy Sustainable Development Issues In China
}

\author{
Dong Dou
}

College of Business \& Management, North China Electric Power University, Baoding 071003, China email: 1105965831@qq.com

Keywords: Energy Economy, Sustainable Development, Energy Strategy

\begin{abstract}
In the case of economic globalization and polarization of world politics, the protection of energy supply and the establishment of energy security supply system have become the world's energy strategy of the starting point and the core content. Based on the sustainable development and energy economy, this paper attempts to put forward the strategy of sustainable development of energy economy under the new situation, and provide reference for the development of energy economy.
\end{abstract}

\section{Sustainable Development And Energy Economy}

With the rapid development of China's economic construction, energy has become the focus of attention. How to develop the strategic issues of China's energy industry in the concept of sustainable development, needs to analyze the formation of sustainable development and the status quo of China's energy industry[1].

China is the largest developing country in the world, which is also the world's second largest energy producer and consumer of energy. At present more and more energy in China has become the bottleneck of China's peaceful rise and establishment of a socialist harmonious society. The correct understanding of the international background of the problem of energy Chinese, scientific grasping of the history and current situation of Chinese energy development, accurate analysis of the intrinsic relationship between China's energy and economy, science to predict changes in China's energy demand, objective analysis on energy consumption and efficiency issues in China and puts forward policy suggestion have important strategic significance to China's stable and rapid economic development[2].

\section{The Factors Affecting the Sustainable Development of Energy in China}

The Imbalance of Energy Supply. The long term development of energy supply shortage, especially the shortage of high quality energy supply. China's coal supply and demand is basically balanced, but in recent years there has been an oversupply. Output imbalance, coal transportation to the west east coal, coal transportation from north to South and exit. Oil supply is relatively tight, while domestic oil has been unable to meet the demand. The direction is north oil to the south, East and west oil, and import supplement. Natural gas supply and demand tension has been eased, but the prominent problem is that the production area is not coordinated. [3]

The Uneven Distribution of Energy Resources and Development Conditions. From the view of resource distribution, it is very uneven. Coal resources are mainly distributed in the northwest and North China, while the oil is mainly distributed in the Bohai Bay, Songliao, Tarim, Junggar four basins and offshore shelf basin. And natural gas is mainly concentrated in the three basins of Tarim, Bohai Bay and Sichuan. The development of hydropower resources is mainly distributed in the southwest region. The conditions of energy development is poor. [3]

The Resource Structure is not Reasonable. For a long time, primary energy production and consumption structure in China is dominated by coal, and its dominant position remains unchanged. This energy structure is not reasonable. From the perspective of energy supply, the proportion of coal has always maintained at a higher level. [3]

The Environmental Pollution is Serious. Coal based energy production and consumption 
structure has brought a series of problems, especially the serious environmental pollution. Because of the extensive exploitation and utilization of coal, the coal contains mineral impurities and harmful toxic elements, which cause serious damage to the natural environment. In the coal mining process of land resources damage, and because the exclusion of water and gas and water and the atmosphere caused varying degrees of damage; emission during coal combustion of gas and dust is the culprit of air pollution. In addition to coal pollution, oil is also one of the sources of environmental pollution. Oil and its products in the combustion caused by photo chemical smog, nitrogen oxide pollution, sulfur pollution, carbon dioxide pollution and cause acid rain and so on. A large number of automobile exhaust emissions of gasoline, is one of the factors of urban air pollution. As shown in Figure 1.

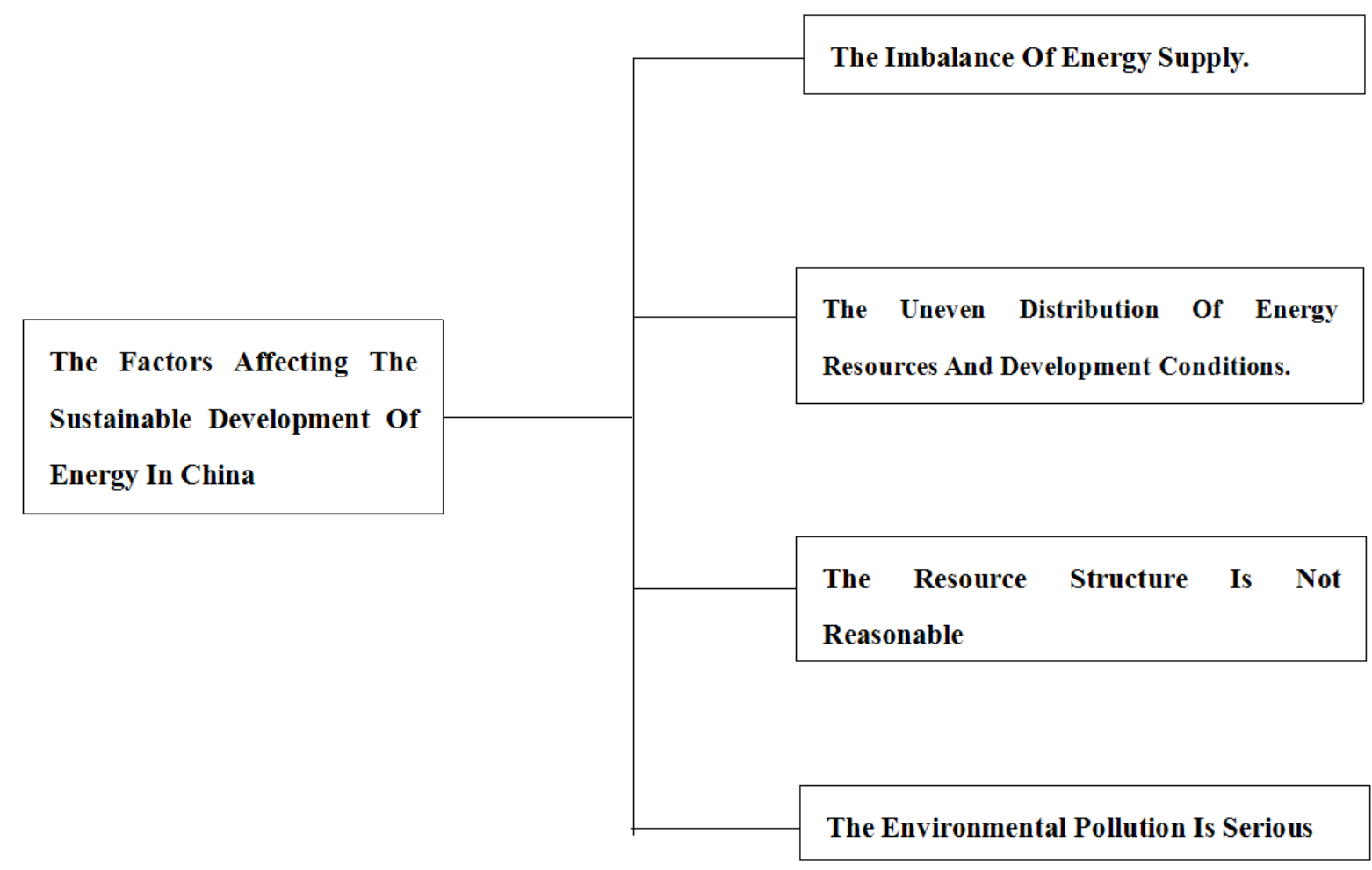

Figure 1.The Factors Affecting The Sustainable Development Of Energy In China

\section{The Future Development Trend of Energy}

According to the specific situation of China's energy and the problems faced, the future development trend of China's energy mainly lies in the following aspects[4]:

1) Energy conservation priority is the focus of China's energy development strategy. If China adopts the policy of strengthening energy conservation and improving energy efficiency, energy consumption can be reduced by I 5\% by 2020, so that the potential of energy saving is an important guarantee to achieve sustainable development. Energy conservation priority, taking into account the development is not only the need of China's energy development, but also the inevitable trend of China and the world economic development.

2) Development of clean coal technology, to achieve a diversified energy structure. In terms of China's energy cost source reserves or production status, in the coming decades of coal will still be the basic energy of our country, therefore, to find a balance between the main sources of pollution and environmental pollution in coal is the main provider of energy, clean coal making technology has important significance for the development of our country energy. At the same time, the effective use of the international energy market, the development of renewable energy and new energy sources are the main ways to achieve structural diversity.

3) Both environmental and energy development. The study of mechanism for the coordinated development of energy products among the rapid development of the environment of the second 
chapter 11 breaking energy and the economy is bad to make our living environment deteriorated sharply, but the energy development has its inherent social standards and rules, any standard beyond the social economic development will pay a heavy price, therefore, in the process of energy development in consideration of the environmental constraints are bound to choose.

4) Transformation of functions, which is to speed up the process of marketization of energy industry. The lag of the energy system reform has seriously affected the efficiency of energy development, to a certain extent, has become the constraints of China's economic development and institutional reform. Therefore, to solve the problem of market reform in the field of energy, and to play the role of market regulation is the guarantee to realize the harmonious development of society, economy and energy. As shown in Figure 2.

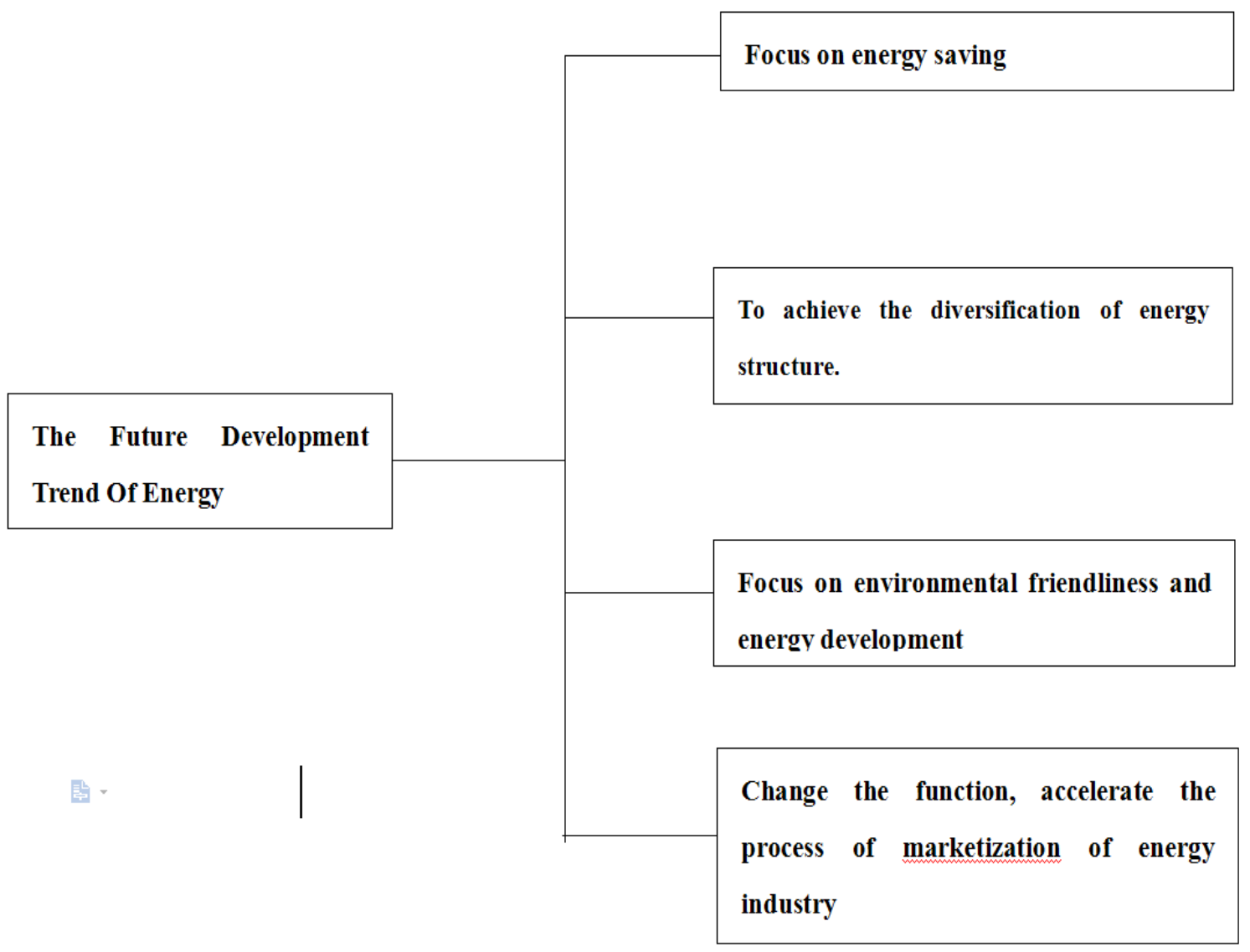

Figure 2.The Future Development Trend Of Energy

\section{The Strategy to the Sustainable Development of China's Energy}

Energy conservation and development simultaneously, efforts to improve energy efficiency and energy efficiency is one of the most effective and economical way to develop China's energy. Although with the progress of science and technology, energy consumption per unit of product and energy consumption per unit output value has decreased, but the energy saving potential is still very great. Good energy-saving work should pay attention to the application of science and technology in all aspects of the whole process from the energy resources exploitation and processing, storage and transportation to the terminal, improve the recovery efficiency and to highlight the main end use energy efficiency[5].

To strengthen the exploration of energy resources, improve energy resources self- assurance degree of China's energy resources is rich, but the resources into reserves proportion is not big, show that our country is not high degree of exploration, great potential for development. To increase the oil, natural gas, coal and other energy exploration efforts, broaden the exploration areas, efforts to extend new areas and new horizons, new areas, focus on the new discovery and discovery, provide high quality reserves for the steady growth of oil and natural gas, coal and other energy 
production. Efforts to increase the number of reserves available for industrial applications, improve the degree of assurance of energy resources.

Actively participate in the international oil and gas exploration and development, make full use of foreign resources, establish stable overseas petroleum production base and export market of energy resources distribution imbalance, determines the international energy resources; global economic integration, to create the conditions for the sharing of resources.

To the development and utilization of new energy and renewable resources in the development of new energy and renewable resources, is not only an important way to solve rural energy supply, more is to improve and optimize the energy structure, an urgent requirement to realize sustainable development.

China's new energy and renewable energy resources are very rich. The main factor that affects the development of new energy and renewable energy is the technology is still not guaranteed new energy and renewable energy applications to obtain economic benefits, the overall level of industrialization is low. Therefore, in order to speed up the development and utilization of new energy and renewable energy in China, give full play to its role in optimizing the energy structure, environmental protection, etc[6].

\section{The End of the Language}

In today's economic globalization, the world's political pattern of multi polarization, to protect the sustainable supply of energy, the establishment of energy security supply system has become the starting point and the core content of energy strategy. At present, China is in a period of rapid economic development, according to China's economic development goals, by the middle of this century, China will reach the level of the world's moderately developed countries, the basic realization of modernization. In the thirty years of energy demand will continue to grow, how to safeguard China's energy sustainable and effective supply, meet the growing demand for energy, building energy security system in our country, to realize the sustainable development of national economy and society, is a long-term and arduous strategic task.

\section{References}

[1] Ma Zhen. New situation under the sustainable development of energy economy strategy [J]. China Economic and Trade Guide, 2016,05: 10-42.

[2] Zhou Kai. Empirical Study on the Relationship between Energy Consumption and Economic Growth [D]. Chongqing University, 2013.

[3] Liang Kai, Lan Jingzhi. China's energy sustainable development countermeasures analysis [J]. Land and Resources, 2003,07: 23-25.

[4] Guo Jin Tong. Energy economy dynamic analysis and energy efficiency level [D]. Tianjin University, 2007.

[5] Liu Li.Study on regional sustainable development under the background of globalization [J]. World Geography Research, 2002,04: 26-32.

[6] Li Meifang. Countermeasures for regional economic development strategy adjustment under the background of economic globalization [J]. China Collective Economy, 2009,01: 40-41. 